\title{
Allegion and the University of Indianapolis: Automatic Lock Testing System
}

$\begin{array}{ccccc}\text { Alysa Epperson* } & \text { Elijah Knox } & \text { Brian Galliher } & \text { Dillon Hines } & \text { Miles Furr } \\ \text { University of } & \text { University of } & \text { University of } & \text { University of } & \text { University of } \\ \text { Indianapolis } & \text { Indianapolis } & \text { Indianapolis } & \text { Indianapolis } & \text { Indianapolis } \\ \text { eppersonap@ } & & & & \\ \text { uindy.edu } & & & \end{array}$

During the 2020-2021 year, senior level students from the R.B. Annis School of Engineering (RBASOE) partnered with Allegion to create an automatic lock testing system for two models of locks. Using Allegion's FFTA (Firmware Functional Test Automation) core unit, students developed a robotic testing setup to provide credentialed inputs and capture outputs for two models of locks. Mechanically, the system will accommodate 4 locks, two each of the NDETM and LETM locks, with the potential to scale to other Allegion products as needed. In Phase I of the project, students met with Allegion to identify their needs. These needs were translated into engineering requirements, from which three design alternatives were generated in Phase II. In Phase III students began to prototype the automatic lock testing system, and run preliminary tests for functionality. In the final phase, Phase IV, final tests were conducted to validate the design before sending to the client for use. In addition to the physical system, students handed over an operations manual detailing information on optimal operation, system safety, and system maintenance.

Throughout this project, students implemented the Design for Six Sigma (DFSS) and Waterfall project management methodologies to guide the design process. Within the R.B. Annis School of Engineering (RBASOE), these methodologies have been adapted into the DesignSpine process. 